\title{
GENDER MATCHING AND COMPETITIVENESS: EXPERIMENTAL EVIDENCE
}

\author{
Nabanita Datta Gupta ${ }^{\mathrm{a}}$ Anders Poulsen $^{\mathrm{b}} \quad$ Marie Claire Villeval $^{\mathrm{c} \#}$
}

\begin{abstract}
This paper experimentally investigates if and how people's competitiveness depends on their own gender and on the gender of people with whom they interact. Participants are given information about the gender of the co-participant they are matched with, they then choose between a tournament or a piece rate payment scheme, and finally perform a real task. As already observed in the literature, we find that significantly more men than women choose the tournament. The gender of the co-participant directly influences men's choices (men compete less against other men than against women), but only when the gender information is made sufficiently salient. A higher predicted competitiveness of women induces more competition. Giving stronger tournament incentives, or allowing the participants to choose the gender of their co-participant, increases women's willingness to compete, but does not close the gender gap in competitiveness.
\end{abstract}

JEL codes : C70, C91, J16, J24, J31, M52.

Keywords: Competition, gender, tournament, piece rate, matching, experiment.

${ }^{a}$ Department of Economics, Aarhus School of Business, Aarhus University, Frichshuset, Hermodsvej 22, DK-8230 Aabyhoej, Denmark and Institute for the Study of Labour (IZA), Bonn, Germany.

E-mail: ndg@asb.dk.

${ }^{\mathrm{b}}$ School of Economics and Centre for Behavioural and Experimental Social Science (CBESS), University of East Anglia, Norwich NR4 7TJ, United Kingdom. E-mail: a.poulsen@uea.ac.uk.

${ }^{\mathrm{c}}$ University of Lyon, F-69007, Lyon, France; CNRS; GATE Lyon St Etienne, F-69130, Ecully,

France; Institute for the Study of Labour (IZA), Bonn, Germany; CCP, Aarhus, Denmark. GATE: 93, Chemin des Mouilles 69130 Ecully, France. E-mail: villeval@gate.cnrs.fr.

${ }^{\#}$ Corresponding author

We are grateful to the editor and two anonymous referees, G. Charness, R. Croson, W. Güth, D. Neumark, P. Oyer, E. Meyersson Milgrom, A. Riedl, R. Slonim, and P. Wakker for extremely useful comments and suggestions. We have also benefited from comments by participants at the EALE conference in Prague, the ESA International meeting in Montreal, the ESPE conference in Paris, the workshop on gender and the labor market at the University of Stanford, the Max Planck Institute workshop in Ringberg - Tegernsee, and at the Tinbergen Institute in Amsterdam. We thank R. Zeiliger for programming the experiment. Financial support from the French Ministry of Social Affairs (DREES-MiRE), from the National Agency of Research (ANR, RHISE program, $n^{\circ} 045-675 / 50.0520$ ), and from the Danish Council for Independent Research in the Social Sciences is gratefully acknowledged. 


\section{INTRODUCTION}

Men and women hold different types of jobs and are employed in different occupations. They also tend to work under different incentive systems, with women being compensated by piece rate payment schemes more frequently. ${ }^{1}$ Relatively few women hold top corporate positions, although in many countries women's educational attainment now exceeds men's. ${ }^{2}$ Fewer women than men have started up their own business (according to the Global Entrepreneurship Monitor, in 2002 in the U.K., 3.1\% of the female population and $6 \%$ of the male population contributed to start-up activities; the same year in France, only $26 \%$ of start-ups were created by women - SINE survey, INSEE). Women are also less likely to run for elections, and they represent a low percentage of seats in national parliaments (according to the InterParliamentary Union, in 2006 they represented $19.7 \%$ in the U.K., $18.5 \%$ in France, and $16.3 \%$ in the US).

In order to explain these gender differences economists have considered supply- and demand-side explanations. Demand-side explanations focus on discrimination (see Altonji and Blank (1999) for a review of these theories, Neumark, Blank, and Van Nort (1996) or Goldin and Rouse (2000) for empirical evidence). Supply-side explanations usually emphasize the role of women in the family and its impact on human capital investment and career choices (Mincer and Polachek, 1974; Polachek, 1981). A more recent literature analyzes if there are gender differences in competitiveness, investigating both the effect of gender on the productive efficiency of incentives and the effect of gender on the selection of competitive incentives. Gneezy, Niederle, and Rustichini (2003) show that men, in contrast to women, perform better in competitive settings than when paid a piece rate.

\footnotetext{
${ }^{1}$ Goldin (1986), Brown (1990), Heywood, Siebert and Wei (1997), Heywood and Jirjahn (2002), and Jirjahn and Stephan (2004) provide current as well as historical evidence on the various reasons why females work wore often under piece-rate schemes: piece-rates were historically used as a substitute for monitoring and women had higher turnover/shorter expected tenure; piece-rates also respond to a higher need for flexibilityamong women due to family constraints; they lessen the possibility of discrimination because they are based on objective performance measurement.

${ }^{2}$ See, for example, Bertrand and Hallock (2001) and Blau, Simpson, and Anderson (1998).
} 
Niederle and Vesterlund (2007) reveal a different tendency of men and women to choose to be rewarded based on relative performance rather than on the basis of one's own performance only. Women tend to shy away from competition. The reasons behind these intriguing results are still poorly understood and they have inspired many other studies. In particular they lead us to investigate the sensitiveness of women's competitiveness to the environment. In our laboratory experiment, participants also have to choose between a piece rate and a tournament payment scheme before performing a task. The novelty of our experiment is that we measure, conditional on a person's own gender, the impact of gender matching on the person's competitiveness. Compared to Niederle and Vesterlund (2007), we can measure how beliefs regarding potential competitors' choices influence individuals' decisions.

There are several reasons why individuals in competitive situations may perceive other individuals' gender to be relevant. First, they may believe that the ability or payment scheme choices of men and women differ, which can lead them to condition behavior on other individuals' gender. Second, they may use their own and the other participant's gender as a coordination device (see Knight 2002, and Holm 2000). Third, some individuals may, regardless of beliefs about underlying fundamentals and gender-based conventions, have preferences that induce them to treat men and women differently. Our experiment, while not designed to cleanly distinguish between these mutually nonexclusive explanations, is designed to analyze in the laboratory whether information on the gender of a potential competitor influences the decision to compete or not.

An important experimental design choice was how to provide gender information. ${ }^{3}$ We began by employing an indirect procedure: Participants were given pseudonyms that

\footnotetext{
${ }^{3}$ Gender is typically revealed in experiments via visual contact (see, e.g., Cadsby and Maynes, 1998; Eckel and Grossman, 2001, 2008; Gneezy et al., 2003; Niederle and Vesterlund, 2007) or explicitly mentioned in the instructions (Holm, 2000; Slonim and Garbarino, 2007).
} 
corresponded to their gender, and they learned each other's pseudonyms before making decisions, but it was not made common knowledge to participants in the instructions that a pseudonym was male (female) if and only if the person in question was a man (woman). We made this choice because we wished to avoid generating experimenter demand effects (subjects conclude that the experiment is about gender which can generate irrelevant or artificial effects). Using this indirect approach, any finding that gender information mattered could be taken as being genuine and robust. A potential problem with this procedure is that any non-significant findings about the role of other the participant's gender can be attributed as much to the lack of common knowledge about the one-to-one mapping between pseudonyms and gender as to the absence of any genuine role played by knowing the other participant's gender. We therefore ran additional sessions where we used a more direct gender information revelation mechanism: Subjects were informed that pseudonyms represented gender. We refer to these gender information revelation mechanisms as the Weak and Strong information procedures, respectively. Our findings show that the behavior of men is sensitive to the procedure used.

Concerning the effects of the individual's own gender, we find that in the Weak gender information procedure more than half of the men, but only a third of the women choose the tournament payment scheme. The gender gap in competitiveness is 26 percentage points (20 points in the Strong information procedure). This is comparable with the finding in Niederle and Vesterlund (2007). In order to understand what causes this difference, we measure participants' risk attitude and elicit their beliefs about other participants' pay scheme choices and their performance, all conditioned on the others' gender. ${ }^{4}$ These beliefs can matter, for if an individual believes that her co-player will choose the piece rate, then she should choose the tournament even if she believes the other is better at

\footnotetext{
${ }^{4}$ Men and women have been observed to differ in their degree of risk aversion (Eckel and Grossman, 2008; Charness and Gneezy, 2007; Croson and Gneezy, 2009).
} 
performing the task. We find that risk influences only women's choices: the women who choose the tournament are significantly less risk-averse than those who choose the piece rate. In contrast, men are not influenced by their risk attitude. Even after controlling for ability, beliefs and risk attitudes, men compete significantly more than women.

We observe a direct effect on behavior of knowing the other person's gender, but only for men and only for the Strong information procedure. Controlling for beliefs about the other person's ability or expected choice, in this treatment men compete less when matched with a man than when matched with a woman. This accords with the gender stereotypical convention found in Holm (2000). This direct effect provides evidence that men, under the Strong procedure, are driven by gender-conditioned preferences similar to a preference-based taste for discrimination. In contrast, women's choices are not directly influenced by other participants' gender. Thus, we find only partial evidence that individuals' own and others' gender serve as an equilibrium selection device in our strategic situation. Under the Weak information procedure there is no direct effect of other participants' gender on choices.

Beliefs about other individuals' degree of competitiveness vary with their gender and affect the individual's own behavior. The more men or women matched with a woman believe that women compete the more likely they are to choose the tournament themselves. Moreover, women compete less the more able they think both men and women are, while men are less likely to compete only when they are matched with a woman and they believe the women's predicted ability is high. Summarizing all the above, gender information affects the participant's own behavior, but the magnitude of the effect and the channels through which it works (direct or via gender-conditioned beliefs) depend on the participant's own gender and on the gender information procedure. 
An important question is if participants made choices that (approximately) maximized their expected earnings given the empirical distribution of pay scheme and effort choices. Under the Weak gender information procedure, we find that men's payment scheme choices are more optimal than women's. It is not the case that 'men compete too much'. Rather, 'women compete too little'. Under the Strong information procedure the same results hold in encounters with women, but there are some differences in encounters with men. Since under the Strong procedure men tend to compete less against men and more against women than under the Weak information procedure, we observe under the Strong procedure in encounters with men that more men suboptimally choose the piece rate, and more women optimally choose the piece rate.

Last, we study whether increasing the expected payoff of the tournament or allowing participants to choose their potential opponent's gender before choosing their payment scheme reduce the gap in competitiveness. We find that each of these changes increases women's competitiveness, but they are not sufficient to close the gender gap in competitiveness.

The rest of the paper is organized as follows. Section 2 describes the related experimental literature. Section 3 presents the game and gives some theoretical predictions. Section 4 describes the experimental design and Section 5 reports the results. Section 6 considers the optimality of the observed choices. Section 7 examines the impact on competitiveness of changing the structure of incentives or allowing individuals to choose the gender composition of their environment. Section 8 concludes.

\section{RELATED LITERATURE}

Gneezy, Niederle and Rustichini (2003) let participants perform a maze solving task under an exogenous piece rate or under an exogenous tournament payment scheme. They find 
that men solve significantly more mazes under the tournament than in the piece rate scheme, whereas the outputs of women are not significantly different. Women work harder when placed in an all-female group compared to a mixed gender group. Gneezy and Rustichini (2004), using a field experiment with school children racing against each other, obtained essentially the same result: boys perform better than girls when racing against someone else, but not when the children run alone. Ivanova Stenzel and Kübler (2005) show that women perform best when competing in all-women teams against allmen teams whereas men perform best in mixed teams.

Niederle and Vesterlund (2007) let participants choose between a piece rate and a tournament payment scheme. They find a gender gap in tournament choice as women tend to shy away from competition (see also Vandegrift and Brown (2005), Vandegrift and Yavas (2009), Dohmen and Falk (2010)). They show that this gender gap cannot be explained by differences in ability. Moreover, although men are more overconfident than women about their relative ranking in the group, a large gender gap remains after controlling for these differences.

The recent literature has provided pieces of evidence mainly in favor of a cultural origin of these gender differences in competitiveness. Gneezy et al. (2009) show that in matriarchal societies in India women are more likely to compete than men, whereas they found the opposite in patriarcal tribes in Tanzania. The cultural explanation is also supported by Dreber et al. (2009) who cannot replicate the gender gap in competitiveness with children in Sweden, possibly because this society is more egalitarian than others, and by Booth and Nolan (2009) who find that girls from single-sex schools in the United Kingdom are more willing to compete than girls from co-educational schools. In a recent study, Sutter and Rützler (2010) study the competitiveness of three to eighteen-year old children. They find that the gender gap emerges early in life, from the age of five, but it is 
not present in younger children. This indicates the importance of social learning in the emergence of gender differences in competitiveness. On the other hand, Wozniak et al. (2010) find that women who are in a low-hormone phase of the menstrual cycle are less likely to compete than those who are in the high-hormone phase of their cycle and the latter do not compete less than men. However, the correlation between women in low hormone phase and women's unwillingness to compete is not necessarily evidence of a biological origin of such gender differences in competitiveness if this result is partly driven by a stereotype threat induced by mestruation. Overall, these studies focus on the role of gender, but they do not explore the potential influence of other individuals' gender on the decision of an individual to compete or not to compete.

The relevance of other participants' gender for economic decisions has been documented in other situations, such as bargaining (Ayres and Siegelman, 1995; Eckel and Grossman, 2001; Sutter et al., 2009), in prisoner's dilemma games (Rapoport and Chammah, 1965), and in coordination games (Holm, 2000). These studies conclude that individuals condition their decisions on the gender of the persons they are interacting with. There is, however, consensus neither on the direction of these effects nor on their origin. Some studies conclude that individuals are more aggressive when interacting with a woman, others point to a higher solidarity.

Gneezy et al. (2003) show that women perform better in a tournament when they are faced by women rather than by men. By extension, another novel contribution of our paper is that we study if individuals' competitiveness is affected when participants can choose whom to interact with. Economists have paid little attention to the impact of gender-based partner selection on decision-making. An exception is Slonim and Garbarino (2007). They find that partner selection affects subsequent actions by increasing trust and altruism in a trust and a dictator game. In an investment game, Slonim (2006) finds that 
participants select and invest more in partners of the opposite gender. Using data on coauthorship patterns in top economic journals, Boschini and Sjögren (2007) show that women are twice as likely as men to co-author with women. We contribute to this literature by considering if and how partner selection affects men's and women's payment scheme choices.

\section{THEORY}

\subsection{The game}

Participants are randomly matched in pairs, and each receives information about the other's gender. Each participant then simultaneously chooses either a piece rate payment scheme or a tournament scheme. Each individual is informed about her co-participant's payment scheme choice, and they then perform a maze solving task.

Payoffs. If an individual chooses the piece rate payment scheme, she is paid 4 points for every maze she solves ( 1 point $=0.25$ Euro $)$, regardless of the co-participant's payment scheme choice. If she chooses the tournament, one of two cases occurs:

- If the co-participant also chooses the tournament, the player who produces most mazes gets 6 points for every maze solved. The other participant gets 1 point for every maze solved. In case of a tie, the winner is randomly selected.

- If the co-participant chooses the piece rate, the participant who chose the tournament gets 6 points for every maze she solves.

In other words, if a participant is the only one who chose the tournament payment scheme, he automatically receives the high payment per solved maze. Note also that our payments are not fixed prizes, but payments per unit of output, as in Gneezy et al. (2003) and 
Niederle and Vesterlund (2007). ${ }^{5}$ After the participants have solved mazes for fifteen minutes, each is informed about the number of mazes she has solved and about her payoff, if they won or lost, but he or she does not learn how many mazes the co-participant solved.

\subsection{Theoretical predictions}

We assume that individuals seek to maximize expected money earnings. We consider risk aversion below. We also assume that there are no effects of the chosen scheme on output, that a player knows his own ability, and knows the ability distribution of men and women. Consider, say, a man who can produce $q_{i}$ mazes and who is matched with a woman. The man's optimal choice between the piece rate or the tournament depends on his beliefs about the woman's payment scheme choice and on how much output she is expected to be able to produce. Formally, let $j=1,2, \ldots, n$ index the female abilities (maze outputs). Let $p_{j}$ denote the probability that the woman's ability level is $q_{j}$, and let $p_{j}^{T}$ denote the probability that a woman of ability $q_{j}$ chooses the tournament. The man's payoff from choosing the piece rate is $4 q_{i}$. If he chooses the tournament, his expected payoff can be written as:

$$
\sum_{j=1}^{n} p_{j}\left[6 q_{i}\left(1-p_{j}^{T}\right)+\pi_{i j} p_{j}^{T}\right]
$$

where $\pi_{i j}$ is the man's expected payoff from choosing the tournament when matched with a woman of ability $q_{j}$ who also chose the tournament. We have $\pi_{i j}=6 q_{i}$ if $q_{i}>q_{j}$ (the man wins the tournament), $\pi_{i j}=3.5 q_{i}$ if $q_{i}=q_{j}$ (a tie), and $\pi_{i j}=q_{i}$ if $q_{i}<q_{j}$ (the man loses the tournament). The first term inside the square bracket is the expected gain from being

\footnotetext{
${ }^{5}$ There are, however, several differences between our game and that in Niederle and Vesterlund (2007). In our experiment a participant who chooses the tournament wins if he produces more than the co-participant who also chose the tournament, and a participant wins by default if he is the only one to choose the tournament. In Niederle and Vesterlund's experiment, on the other hand, the performance of someone who chooses the tournament is compared with a 'baseline' performance of all participants, including those who did not choose the tournament, and several people can win the competition. Moreover, whereas in Niederle and Vesterlund beliefs about other participants' pay scheme choices play no role, in our experiment these beliefs can affect decisions. Indeed, in a real setting we expect that people condition their decision to compete on their beliefs regarding the competitiveness of others.
} 
matched with a woman of ability $q_{j}$ who chooses the piece rate; in this case the man, by virtue of being the only one who chose the tournament, gets the high payment, 6 , per maze. The second term is the expected gain when the woman chooses the tournament.

The tournament is an optimal choice for the man matched with a woman of ability $q_{j}$ if the man believes he is better than the woman. But the tournament is optimal even when the man believes he is worse than the woman, if the man believes the woman is sufficiently unlikely to choose the tournament $\left(p_{j}{ }^{T}\right.$ is sufficiently small). Overall, we see that: i) a higher (believed) own ability, and so equivalently a higher own believed relative ability relative to the female abilities, (weakly) raises the expected payoff from the tournament, and so (weakly) increases the likelihood that the tournament payment scheme is optimal; ii) the lower the overall proportion of women who are thought to choose the tournament, the higher is the expected payoff from the tournament payment scheme. Risk aversion makes the safe piece rate option relatively more attractive. Ceteris paribus, we should therefore expect that more risk-averse participants are less likely to choose the tournament.

In our experiment, participants must form beliefs about the proportions of men and women of different abilities they think will choose the tournament (the $p_{j}{ }^{T}$ numbers, see equation 1). In equilibrium, all participants make correct estimates about others' payment schemes and all choose the optimal payment scheme. We felt it would be a cognitively very demanding task to ask participants to estimate the two ability distributions and, for each possible ability level, to estimate the proportion of participants of that ability level who would choose the tournament. We chose instead to estimate beliefs about men and women's ability in a simpler way, namely by asking participants to estimate the average performance of men and of women (see below). 


\section{EXPERIMENTAL DESIGN}

\subsection{The task}

As Gneezy et al. (2003) we use mazes similar to those available at http://games.yahoo.com/games/maze.html. All have same level of difficulty. Participants receive the same mazes in the same order and this is common knowledge. On the computer screen, a marker indicates the current position in the maze and it is possible to restart from any point already reached. Participants could at any time abandon the current maze and move on to a new maze by clicking the 'next' button. The screen also indicates the number of mazes already solved and the time elapsed. Before being informed about the rules of the game, participants practice by solving three mazes.

\subsection{Providing gender information.}

At the beginning of the session the participants complete a demographic questionnaire containing a gender question, and the computer then allocates each participant a pseudonym $^{6}$ that corresponds to his or her own gender.

\section{The Weak gender information procedure}

After two individuals are randomly paired, each participant is informed about the coparticipant's pseudonym, but subjects are not explicitly informed that male (female) pesudonyms are only given to men (women). We use this procedure to preserve anonymity and to minimize biases, such as participants changing their behavior just because of a demand effect. A subject was, however, not explicitly told in the instructions

\footnotetext{
${ }^{6}$ The pseudonyms correspond to the ten most popular names for each gender in 2003 (RNIPP and INSEE). For females the names are: Chloe, Clara, Emma, Aurelia, Lea, Manon, Marie, Océane, Sarah, and Carla. For males the names: Alexandre, Antoine, Clement, Enzo, Hugo, Lucas, Maxime, Quentin, Theo, and Thomas. A similar procedure is used in psychology (see Ingram and Berger, 1977). These names are typically either male or female and there is no ambiguity on the gender associated with any name. They are not known to convey any specific message on the competitiveness of their owner. The participants did not choose their pseudonym and they were not informed on the full list of names.
} 
that a pseudonym always reflected the person's gender, and this was therefore not common knowledge. We cannot exclude the possibility that participants might disregard gender information because they were not certain that the co-participant's pseudonym corresponded to his/her actual gender, or because they may have worried that the other participant had such doubt. To deal with these concerns, we also used a stronger procedure.

\section{The Strong gender information procedure}

We ran two additional sessions where it was made explicit that participants' pseudonyms reflected their gender. Precisely, the instructions stated that "If you are a woman, your pseudonym is a female name, and if you are a man your pseudonym is a male name. Similarly, if your co-participant is a man, his pseudonym will be a male name, and if your co-participant is a woman, her pseudonym will be a female name."

\subsection{Measuring risk attitudes and eliciting beliefs}

Risk attitudes. Risk aversion can influence the decision to choose the tournament payment scheme. $^{7}$ To measure risk attitudes, we use a modified version of the psychometric test in Weber, Blais, and Betz (2002). In a post-experimental questionnaire (see online Supplementary Material, SM2), participants rate the likelihood that they would engage in sixteen domain-specific risky activities on a five-point scale ranging from 1 ("extremely unlikely") to 5 ("extremely likely"). A participant's risk attitude score is computed by summing up her answers to these sixteen items. The higher the score, the more risk-loving the participant is. ${ }^{8}$

\footnotetext{
${ }^{7}$ Women have been found to be more risk-averse than men in financial decision-making (Eckel and Grossman, 2001, Powell and Ansic, 1997; Barsky et al., 1997; Borghans et al. 2009; they invest less (Charness and Gneezy, 2007) or more conservatively (Jianokoplos and Bernasek, 1998). See Croson and Gneezy (2009) for a survey.

${ }^{8} \mathrm{We}$ did not use lottery choices. A psychometric scale is a more neutral elicitation method in the context of our game. Compared to the traditional lottery elicitation procedures, this method seems to give more stable results (Eckel, 2005). In addition, organizing the lottery before starting the game would have focused attention on the risk associated with the tournament choice and could have biased behavior. Organizing it at
} 
Measuring beliefs about ability. Any gender difference in the choice of the tournament could be due to men and women differing in beliefs about relative ability. ${ }^{9}$ After performing the task and receiving feedback on earnings, participants estimate the average performance of men and of women in their session. For simplicity they are asked to do this unconditional on the payment scheme chosen. Each accurate answer pays $€ 1 .^{10}$

Measuring beliefs about payment scheme choices. After having performed the task and received a feedback on own payoff, and after being informed of the numbers of men and women participating in the session, each participant is asked to predict the number of men and the number of women in the session who chose the tournament. Each correct answer is paid $€ 1$. This data allows us to see whether men and women differ in their beliefs about men's and women's payment scheme choices, to see how accurate these beliefs are, and to see if these beliefs influenced people's own choices. ${ }^{11}$ In addition, in our last four sessions, after making his own decision, but before being informed of the actual choice of his co-participant, each participant has to predict the decision of his co-participant to enter or not the competition. This gives us an additional information on the subject's belief at the time of making his decision. The accuracy of this prediction is also rewarded $(€ 1)$.

\footnotetext{
the end of the session would have introduced a risk that subjects' choices in the lottery were conditioned on the risk already taken during the game. In contrast, our questionnaire was based on reported risk behavior in various domains and we assume that the answers were not conditioned on the decisions in the game.

${ }^{9}$ Overconfidence can give excess entry in competition (Camerer and Lovallo, 1999). Exaggerating their control over events, a majority of individuals is unreasonably optimistic about the future (Taylor and Brown, 1988). They overestimate the precision of their knowledge (Lichtenstein et al., 1982). They believe their performance is above the median (Kahneman and Lovallo, 1993). Also, men have been shown to be more overconfident than women in investment decisions (Barber and Odean, 2001).

${ }^{10}$ An alternative procedure would have been to ask the participants to assess their chances of winning the tournament. We did not use this procedure because we sought to collect more detailed data on predicted performance of men and women to measure the potential importance of gender stereotypes. We discuss our elicitation procedure further in Section 5.3.

${ }^{11}$ Previous research has shown that people can suffer from "competitive blind spots" (i.e., a tendency to underestimate the competitiveness of the environment (Camerer and Lovallo, 1999).
} 


\subsection{Logistics}

The experiment was conducted at the GATE laboratory (Groupe d'Analyse et de Théorie Economique) in Lyon, France, using the REGATE software (Zeiliger, 2000). In total 280 undergraduates studying at business or engineering schools (139 men and 141 women) participated in 14 sessions (see Appendix 1). 12 (2) sessions used the Weak (Strong) gender information procedure. Each session involved 20 participants, with at least 9 participants of the same gender. 57 mixed pairs, 46 female pairs, and 37 male pairs were matched. The main treatment involved 70 women and 70 men.

Upon arrival, the participants were randomly assigned to a computer. They answered a computerized demographic survey. The first part of the instructions (see online Supplementary Material, SM1), describing the nature of the task, was distributed and read aloud, and participants then practiced by solving three mazes. The second part of the instructions was then distributed and read aloud. The participants filled out a questionnaire in order to check their understanding and any questions were answered in private. Each participant then received a pseudonym, was randomly matched with another participant, and learned the co-participant's pseudonym. Participants chose their payment scheme and received feedback on their co-participant's decision. Then participants performed the task for 15 minutes. They were then informed about their earnings, but not about the coparticipant's performance or earnings. We elicited their beliefs regarding the choice and performance of men and women in the session. Finally, participants reported their risk behaviors.

On average a session lasted 70 minutes. The participants were paid at the rate 1 point $=$ 0.25 Euro. In addition, they were paid a show-up fee of $€ 2$, plus $€ 2$ for the questionnaire on risk attitudes, and up to $€ 5$ for accurate predictions. On average, women earned $€ 16.90$ 
(SD 5.82) and men $€ 19.08$ (SD 7.92). The payments were made in cash in a separate room.

\section{RESULTS}

Tables $1 \mathrm{a}$ and $1 \mathrm{~b}$ present descriptive statistics for the payment scheme choices and average number of mazes solved, for each gender and conditional on the gender of the coparticipant. Table 1a (1b) is about the Weak (Strong) gender information procedure.

\section{(Table 1 about here)}

\subsection{The gender gap in competition and the influence of the co-participant's gender}

Tables $1 \mathrm{a}$ and $1 \mathrm{~b}$ show a large gender gap in payment scheme choices: using the Weak gender information procedure, $34 \%$ of women and $60 \%$ of men enter the tournament; using the Strong information procedure, the respective percentages are $25 \%$ and $45 \%$. In both treatments, the percentage of women choosing the tournament is significantly lower than the $50 \%$ that would have been expected if choices were random (binomial tests: $p=0.032$ under the Weak information procedure and $p=0.041$ under the Strong information procedure, two-sided). In contrast, the corresponding percentages of men are not significantly different from 50\% (binomial tests: $p=0.203$ under the Weak procedure and $p=0.823$ under the Strong procedure, two-sided).

Overall, there is no significant difference in the choice of tournament between the Weak and the Strong conditions, both for women (M-W: $p=0.467)$ and for men $(p=0.257)$. This allows us to pool the data from both conditions. Overall, the gender gap is statistically significant ( $\chi^{2}$ test: $p=0.004$; two-sided Fisher's exact test: $p=0.006$ ).

As regards the impact of gender matching under the Weak information procedure, Table 1a indicates that $34.37 \%$ of women choose the tournament payment scheme when matched with another woman, and $33.33 \%$ of women do the same when matched with a man. The 
difference is not significant $\left(\chi^{2}\right.$ test: $p=0.941$; two-sided Fisher's exact test: $p=1.000$ ). In this condition, $55.56 \%$ of men choose the tournament when matched with a woman and $62.50 \%$ of men make the same choice when matched with a man; the difference is not significant either ( $\chi^{2}$ test: $p=0.630$; two-sided Fisher's exact test: $\left.p=0.765\right)$. Turning to the Strong gender information procedure, Table $1 \mathrm{~b}$ indicates that $25 \%$ of women choose the tournament payment scheme both when matched with another woman or with a man, while $62.50 \%$ of men make the same choice when matched with a woman and $33.33 \%$ when matched with another man. Although the proportion of men entering the competition is twice as high when matched with a woman than with a man, the difference is not statistically significant ( $\chi^{2}$ test: $p=0.199$, two-sided Fisher's exact test: $p=0.362$ ).

Mann-Whitney tests (M-W thereafter) comparing the choice of the payment scheme in the Weak and the Strong information conditions for each gender and each gender matching configuration indicate no significant differences, except when considering the choice of the tournament by men who are matched with another man $(p=0.087) .{ }^{12}$ We next turn to an econometric analysis of the data to identify the determinants of competitive choices.

\subsection{Explaining the gender gap in tournament choice}

We estimate four probit models to identify the determinants of the probability to choose the tournament. The first two probit models are estimated on the pooled sample of men and women, in order to measure the overall impact of gender and gender matching on pay scheme choices. In model (1) we introduce the separate effects of the participant's and the co-participant's gender on tournament choice, while in model (2) we allow for the interaction of own gender and partner's gender by including all possible gender configurations of the pairs, with the woman-man pairs as the reference. Model (2) is also

\footnotetext{
12 The $p$-value is equal to 0.746 for men matched with a woman, 0.677 for women matched with a man, and 0.557 for women matched with another woman.
} 
estimated on each sub-sample separately to test whether some variables have a different impact on men and women (model (3) is for the sub-sample of women and model (4) is for the sub-sample of men). In models (3) and (4), the reference category is the mixed pairs. In the four models we have pooled the data from the Weak and the Strong gender information procedures and we have included a dummy variable indicating the Strong gender information procedure. This variable is interacted with both the subject's gender variable and the co-participant's gender variable.

In all models, we include as an explanatory variable the participant's risk score; the higher the score, the less risk-averse the participant. In the first two models this score is interacted with the participant's gender to allow for a different impact of risk score by gender on the choice of the tournament. Also included is the participant's belief about the proportion of men (women) choosing the tournament (excluding him or herself) if paired with a man (woman), and his or her beliefs about the average maze output of men (women) (excluding him or herself) if paired with a man (woman). A participant should be more likely to choose the tournament the less likely he thinks that his co-participant will choose the tournament. Similarly, he should be more likely to enter the tournament the less able he thinks that his co-participant is. We add the participant's actual performance as a control for own ability. We make two assumptions when doing so. First, we assume that effort is the same in both payment schemes and that differences in performance under the piece rate and the tournament result from the self-selection of participants with various abilities. ${ }^{13}$ Second, we assume that the participants are aware of their own ability. Lastly, we control for the participant's age and his or her experience with economic experiments. These regressions test whether any gender effect remains when we control for both own

\footnotetext{
13 Participants have an incentive to provide the maximum level of effort whatever the payment scheme chosen since they are always paid as a function of the number of mazes solved.
} 
characteristics and beliefs about others conditional on the co-participant's gender. Table 2 displays the results of these regressions (mean values in Appendix 3).

\section{(Table 2 about here)}

Gender. Model (1) in Table 2 shows that in both models, when we control for risk attitude, ability, and beliefs, men choose the tournament significantly more (at the $1 \%$ level) than women, whatever their co-participant's gender. Model (2) indicates that, compared to women matched with a man (the reference category), both men matched with a man and men matched with a woman (especially under the Strong gender information procedure) are significantly more likely to choose the tournament. Also, women matched with a woman do not compete more than when matched with a man.

We also find that men's probability of choosing the tournament is directly influenced by their co-participant's gender when the information on gender is provided via the Strong gender information procedure. More precisely, men matched with men compete significantly less under the Strong than the Weak information procedure (see models (1) and (4)). Since in both models we control for risk attitude, ability and beliefs, these findings indicate that men's decisions are conditioned by their opponent's gender when the gender information is provided in a sufficiently salient manner. This is consistent with the results from the non-parametric tests. ${ }^{14}$

Risk attitude. Table 2 shows that risk attitudes influence the payment scheme choices of women, but not of men. Women are more likely to choose the tournament the higher is their risk score and this is highly significant (see model (3)). The decision of men is, however, not affected by their risk attitude (see model (4)). Considering the raw data from

\footnotetext{
${ }^{14}$ Mann-Whitney tests indicate that the same number of women matched with a man choose the tournament under the Strong and the Weak information procedure $(p=0.677)$; they reach the same conclusion for both women $(p=0.557)$ and men $(p=0.756)$ when paired with a woman. In contrast, when paired with another man, less men choose the tournament when information on gender is more salient $(p=0.087)$.
} 
both Weak and Strong information procedures (see the score distributions in Appendix 2), we find that the average risk score is higher for men $($ mean $=49.36$, S.D. $=6.45)$ than for women $($ mean $=48.33$, S.D. $=6.80)$. The difference is, however, not significant according to a Kolmogorov-Smirnov test for equality of distribution functions ( $p=0.826$, exact). The women who compete are significantly less risk-averse than the non-competing women $($ means $=50.86$ and 47.17 respectively, S.D. $=7.99$ and 5.90; Kolmogorov Smirnov test: $p$ $=0.066$, exact). In contrast, the men who choose the tournament are not less risk-averse than those who choose the piece rate $($ mean $=49.87$ and 48.71 , respectively, S.D. $=6.59$ and 6.30; Kolmogorov Smirnov test: $p=0.759$, exact). Variations in risk preference thus explain variations in women's choices, but not men's. ${ }^{15}$

Beliefs about others' payment scheme choices. In both models an expectation of higher female competitiveness (the "predicted entry rate of women if female co-participant" variable) significantly increases the likelihood of choosing the tournament payment scheme for both men and women. Only women are influenced, but marginally so, by their beliefs regarding men's competitiveness. These results are surprising because according to the model outlined in Section 3.2 a participant should be more likely to choose the tournament the more he or she believes that the co-participant will stay out of the competition. One possible explanation is that participants feel it is normatively less acceptable to shy away from competing against a woman when one believes that women will compete. Pooling data from both the Weak and Strong information procedures, descriptive statistics indicate that $91.43 \%$ of women and $88.57 \%$ of men believe that the percentage of men choosing the tournament is higher than the percentage of women making the same choice (M-W: $p=0.575$, two-tailed). On average women and men have the same beliefs about women's likelihood of choosing the tournament payment scheme

\footnotetext{
15 If our risk attitude elicitation method underestimated gender differences compared to lottery choices, we should expect that this difference in choices conditional on the risk score would be even larger.
} 
(42.46\% and $39.36 \%$, respectively; $\mathrm{M}-\mathrm{W}: p=0.139)$, but women predict a marginally higher competitiveness of men than men themselves $(66.94 \%$ and $61.00 \%$, respectively; $p$ $=0.083)$. These beliefs are quite accurate. The differences in men's and women's beliefs are, however, too small to explain the gender gap in competition.

Beliefs about abilities. Beliefs about others' ability receive the predicted negative sign and this variable is significant at the $1 \%$ level in both models. Regressions on the gender subsamples show, however, that these beliefs mainly influence women's decisions, while men only react to the predicted average ability of women when paired with a woman, and only marginally so. The raw data show that on average women believe that men solved 11.52 mazes $($ S.D. $=3.05)$ and other women solved 9.93 mazes $($ S.D. $=2.85$, Wilcoxon test: $p<0.001)$; men believe that other men solved 11.73 mazes $($ S.D. $=2.70)$ and women solved 10.15 mazes (S.D. $=2.52$, Wilcoxon test: $p<0.001$ ). Average male and female predictions about men's and women's ability are thus similar (M-W: $p=0.250$ and $p=0.390$, respectively). In addition, $93.33 \%$ of women and $95 \%$ of men expect men to be more able than women (M-W: $p=0.698)$. However, men only avoid competing against women but not against men when they expect the latter to be very able, as if taking the risk of losing against an abler woman was bringing additional disutility. ${ }^{16}$

Table 2 also indicates that, controlling for the other variables, more able participants from both genders are significantly more likely to choose the tournament, at the $1 \%$ level. Descriptive statistics indicate that those men who chose the tournament payment scheme solved more mazes (12.50 in a two-person tournament and 14.29 in a single-person tournament) than those who chose the piece rate payment scheme (12.13), whereas for

\footnotetext{
${ }^{16} \mathrm{We}$ found no correlation between the beliefs about entry decisions and those about ability ( $p=0.869$ when the co-participant is a man and $p=0.787$ when she is a woman). This indicates that the participants make a clear distinction between these dimensions. The same regressions as those reported in Table 2 have also been tested without including beliefs about the entry decisions. For women, the opponent's predicted ability still matters whatever the gender of the opponent. For men, the opponent's predicted ability remains insignificant.
} 
women the difference is smaller (11.44 in a two-person tournament, 10.46 in a singleperson tournament, and 11.10 in the piece rate scheme). Tables $1 \mathrm{a}$ and $1 \mathrm{~b}$ give the corresponding numbers for the Weak and the Strong information procedures separately.

Summarizing the above, we find that own gender remains a significant determinant of the decision to compete even after controlling for risk attitude, beliefs and ability. ${ }^{17}$ Also, the co-participant's gender matters directly for men when the information on gender is provided via the Strong gender information procedure, and indirectly through beliefs mainly about women's competitiveness and ability. ${ }^{18}$

\section{THE OPTIMALITY OF PAYMENT SCHEME CHOICES}

The optimal pay scheme choice for a participant is the one that, given the empirical distribution of pay scheme choices and outputs, maximizes the person's expected earnings. In what follows we ignore the unmeasured subjective cost of performing the task and assume people are risk-neutral. Moreover, we assume that a participant would produce the same number of mazes in the non-chosen payment scheme as in the chosen payment scheme. This reflects our previous assumption that a participant's output is a good measure of his inherent ability.

\footnotetext{
${ }^{17}$ When estimating model 1 with only gender, partner's gender, ability, age, experience, and the Strong information procedure, the pseudo $R^{2}$ is 0.081 . Adding the risk and risk*man variables raises the pseudo $R^{2}$ to 0.111 . Adding beliefs about the co-participant's gender entry rate raises it to 0.130 . After adding beliefs about others' ability, the pseudo $\mathrm{R}^{2}$ reaches 0.204 . This confirms the importance of each of these dimensions. 18 The beliefs about entry decisions are measured after participants were informed of their co-player's choice. We have checked that this procedure has not influenced reported beliefs. Mann-Whitney tests indicate that neither women nor men's beliefs on entry rates by gender are influenced by their coparticipant's actual decision. Furthermore, in four sessions participants stated their beliefs about their coparticipant's choice after they had made their own choice, but before they learned the co-participant's choice. We found that expecting the co-participant entering the competition increases (and not decreases) the individual's likelihood of competing, especially if the co-participant is a woman. Eliciting beliefs about their co-participant's payment scheme choice before or after they learned the co-participant's choice leads to the same qualitative analysis. Regarding beliefs about ability, a potential bias could arise from the fact that a participant states his belief after being informed on whether he won or lost the tournament in case both players competed. Mann-Whitney tests show that being informed about one's success or failure does not impact the predictions. Also, there is no significant difference in beliefs between the winners and the losers of the two-person tournaments. We thus believe that there is no noticeable bias in the way we elicited beliefs. Details are available in the online Supplementary Material, SM3.
} 
In order to compute the expected payoff an individual would earn from choosing the piece rate instead of the tournament, we simply multiply his tournament output by the piece rate. To compute what expected payoff a participant would earn from having chosen the tournament instead of the piece rate, we keep the gender configuration fixed and compare the participant's output with the relevant reference group. As an example, consider a woman who was matched with a man and who chose the piece rate. We compute her expected payoff from choosing the tournament by randomly matching her with one of the men who were matched with a woman and who either i) chose the piece rate or ii) who chose the tournament and whose female opponent also chose the tournament. The expected payoff from choosing the tournament is a weighted average of these payoffs. ${ }^{19}$

Table 3 shows, for each of the four gender configurations, the proportion of participants for whom the actually chosen pay scheme was optimal.

\section{(Table 3 about here)}

Consider first the Weak gender information procedure. Among the women who were matched with men and who chose the piece rate, only $16.66 \%$ did so optimally. But in the same encounters the tournament was optimal for $83.33 \%$ of the women who chose this pay scheme. All the women who were matched with other women and who chose the piece rate should have competed instead, and all the women who competed did so optimally. This shows that women compete too little: most would have been better off by choosing

\footnotetext{
${ }^{19}$ More precisely, suppose the woman's piece rate output is $q_{i}$. Let $p$ denote the empirical proportion of men who were matched with women and who chose the tournament. Let $\pi_{F M}^{T T}$ denote the expected payoff to a female of ability $q_{i}$ from being matched with a man when both chose the tournament: $\pi_{F M}^{T T}=\sum_{j} p_{j} \pi_{i j}$, where the summation is over all the outputs of males matched with females where both chose the tournament, $p_{j}$ is the relative frequency of these outputs, and $\pi_{i j}$ is the tournament payoff from matching output $q_{i}$ with output $q_{j}$. The expected payoff from choosing the tournament is then computed as $6 q_{i}(1-p)+\pi_{F M}^{T T} p$. If this payoff exceeds the woman's observed piece rate payoff, $4 q_{i}$, we conclude that she made a sub-optimal payment scheme choice. Otherwise her payment scheme choice is optimal.
} 
the tournament instead of the piece rate. Although all the women who were matched with a woman should have chosen the tournament, only $34.38 \%$ of them did so.

We also see from Table 3 that, when matched with a woman, the tournament is optimal regardless of the participant's own gender. This is true even for participants with very low productivity. The reason is that since only $34 \%$ of the women choose the tournament, a participant who is matched with a woman will profit from choosing the tournament simply because he or she is likely to be the only one who chose to compete.

Compared with women, men behave significantly more optimally. Like women, all the men who in encounters with women chose the piece rate, all did so incorrectly, and like women all the men who in encounters with women chose the tournament did so correctly. But among the men who were matched with men and who chose the piece rate, $58.33 \%$ did so optimally, while the number for women is only $16.66 \%$. And while $90 \%$ of the men who in encounters with men chose the tournament optimally, for women the number is only $83.33 \%$. Combining Table 3 with Table 1a, we find that, overall, $78.12 \%(55.56 \%)$ of men paired with another man (woman) made the appropriate choice. In contrast, only $38.89 \%(34.38 \%)$ of women paired with a man (woman) chose the best payment scheme. On average men earn $24.20 \%$ more than women.

Consider now the Strong gender information procedure. In encounters with women the optimality of the observed choices is the same as for the Weak information procedure: Women are so unlikely to compete that any person, whether man or women, and regardless of her actual ability, should choose the tournament if matched with a woman. The main difference from the Weak information procedure lies in encounters with men. Since men matched with men (women) are less (more) likely to compete under the Strong than the Weak gender information procedure, all the men who chose the piece rate should have chosen the tournament, and all the men who chose the tournament did so optimally; for 
women the piece rate pay scheme becomes correspondingly more optimal. Here, on average men earn $13.82 \%$ more than women.

How much could those who made sub-optimal choices expect to gain from switching payment scheme? We consider the Weak information procedure and randomly select from each of the four gender configurations a participant from the pool who made a suboptimal payment scheme and compute his or her expected gain from switching to the optimal payment scheme, while keeping all other participants' choices fixed. ${ }^{20}$ Table 4 shows the average expected gains for each procedure.

\section{(Table 4 about here)}

Under the Weak information procedure, when matched with a woman, the women (men) who incorrectly chose the piece rate could on average gain $35.8 \%(30.8 \%)$ more from switching to the tournament. Against men, both women and men stand to gain considerable increases in earnings from switching payment scheme. The numbers for the Strong information procedure are qualitatively similar. When matched with a woman, the tournament was never suboptimally chosen, even by low ability individuals. The difference from the Weak information procedure is that the same is now true when men are matched with male opponents. The reason is again that men are less competitive in these encounters than under the Weak information procedure.

\section{CAN ONE INCREASE WOMEN'S COMPETITIVENESS?}

Which policies can increase women's competitiveness and decrease the gap in competitiveness? We first investigate the impact of increasing the monetary incentives offered by tournaments. We then increase the participants' control over their environment by letting them choose their co-participant's gender.

\footnotetext{
${ }^{20}$ In computing these numbers, we have ignored the fact that moving a participant from the sub-optimal to the optimal payment scheme affects the overall distributions of payment scheme choices, and hence affects the expected payoffs of other participants.
} 


\subsection{Increasing the monetary incentives to compete}

In our Incentive treatment we change the payoffs. In three new sessions, involving 30 women and 30 men, the loser's payment was increased from 1 to 1.5 points per maze and the piece rate payment was reduced from 4 to 3 points per maze. The winner's payment remains the same (6 points per maze). This is the only difference from the Baseline treatment with the Weak gender information procedure. Figure 1 displays the percentage of individuals choosing the tournament for each gender configuration in this treatment compared to the Baseline.

(Figure 1 about here)

The percentage of women choosing the tournament is now $63.33 \%$, whereas before it was $34 \%$ and the difference is significant (M-W: $p=0.011)$; the increase is similar whatever the co-participant's gender. But men are also more competitive when tournament incentives are increased, especially when matched with a woman. The percentage of men choosing the tournament increases from $60 \%$ to $93.33 \%$ (M-W: $p=0.001$ ). Therefore the gender gap in competitiveness increases to $30 \%$ while it was equal to $24.28 \%$ in the Baseline and it remains significant $\left(\chi^{2}\right.$ test: $p=0.005$; Fisher's exact test: $p=0.010$, twosided). This shows that women respond to changes in the monetary incentives (it is not the case that women 'just don't like to compete'), but this does not reduce the gap in competitiveness whatever the co-participant's gender.

\subsection{Allowing participants to choose their co-participant}

To see the gender matching preferences and their impact on the gap in competitiveness, we run an additional treatment, Partner Choice, where individuals choose to interact with a man or a woman after being informed on the rules of the game, but before choosing their payment scheme. Four additional sessions involved 41 women and 39 men. Each participant saw on the screen a female and a male pseudonym, each referring to another 
participant in the room. The participant then chose one of these participants to be his or her co-participant. ${ }^{21}$ All other features of the experiment remained the same as in the Baseline under the Weak gender information procedure.

In comparison with the Baseline treatment under the Weak gender information procedure, women but not men are more likely to choose the tournament. The overall percentage of women who choose the tournament increases from $34 \%$ to $53.66 \%$ $(+57.82 \%$; M-W: $p=0.068)$, while the percentage of men increases from $60 \%$ to $74.36 \%$, but not significantly so $(+23.93 \%$; $\mathrm{M}-\mathrm{W}: p=0.157)$. Giving participants more control over their environment reduces the gender gap in tournament choice from 26 (25 if one includes the data from the Strong procedure) percentage points in the Baseline treatment to 20.70 percentage points in the new treatment (a Mann-Whitney test indicates, however, that the difference is not significant, $p=0.570, \mathrm{~N}=11$ ). The choice of the tournament remains, however, significantly different for men and women $\left(\chi^{2}\right.$ test: $p=0.054$; Fisher's exact test: $p=0.066$, two-sided).

Considering participants' partner choices, $68.29 \%$ of women and $71.78 \%$ of men choose to be paired with a woman (the difference is not significant; $\left(\chi^{2}\right.$ test: $p=0.733$, Fisher's exact test, $p=0.810$, two-sided). Both percentages are significantly different from a random choice (binomial tests: $p=0.027$ for women and $p=0.009$ for men). ${ }^{22}$ This makes sense for participants who plan to compete since a large majority of participants believe that women are less able and less willing to choose the tournament. This cannot be the only motivation since the impact of the choice of a female co-participant on competitiveness is only significant for women. Indeed, of the women who choose to be

\footnotetext{
${ }^{21}$ A participant is always matched with the person he chose. To see how the matching works, suppose that participant $\mathrm{X}$ chooses $\mathrm{Y}$, that $\mathrm{Y}$ chooses $\mathrm{Z}$, and that they all choose the tournament. Participant $\mathrm{X}$ 's performance is then compared with Y's. Y is not informed about him/her being chosen by $\mathrm{X}$, and Y's payoff only depends on the comparison between $\mathrm{Y}$ and $\mathrm{Z}$.

${ }^{22}$ These percentages also indicate that the participants considered the pseudonyms as corresponding to the actual gender even in the Weak information procedure; otherwise they would have been indifferent.
} 
matched with another woman, $57.14 \%$ select the tournament, while only $34.38 \%$ of the women who were exogenously matched with a woman made the same decision (M-W: $p=$ 0.079). Those women who chose to be matched with a man choose the tournament more often than in the Baseline ( $46.15 \%$ vs. $33.33 \%)$, but not significantly so $(p=0.477)$. Of the men who choose to be matched with a woman, $75 \%$ select the tournament $(55.56 \%$ in the Baseline; $\mathrm{M}-\mathrm{W}: p=0.175)$; those who chose to be matched with another man choose the tournament more often than in the Baseline $(72.73 \%$ versus $62.50 \%)$, but not significantly so either $(p=0.544)$ (see also Figure 1$){ }^{23}$

Being able to decide whether to work with women rather than men has a stimulating effect on women's competitiveness. This increase in competitiveness cannot be explained by women believing they have a larger chance of winning the competition against a woman than against a man. Indeed, similar regressions than those reported in Table 2 conducted on this treatment only (not reported but available upon request) reveal that the more women believe that women are able on average, the more they choose the tournament $(p=0.096)$. Even in this treatment, the gender of the co-participant does not influence the selection of the tournament ( $p=0.675$ for women and $p=0.823$ for men). A more plausible explanation of the higher competitiveness of women in this treatment is that women tend to be more sensitive to the social context in which they make choices. Having better control over this environment, through the choice of the co-participant's gender, improves their competitiveness. Indeed, as reported in Croson and Gneezy (2009), women would be more sensitive to the social context than men.

Overall, the two policies we have investigated increase women's competitiveness but they are not able to reduce the gap in competitiveness.

\footnotetext{
${ }^{23}$ The conclusions are similar if we pool the data from the Weak and the Strong information procedures.
} 


\section{CONCLUSION}

Niederle and Vesterlund (2007) found that men are more competitive than women. We extend their investigation by asking if these differential competitive tendencies interact with the gender composition of the group. We also find that individuals' own gender matters, after controlling for ability, risk attitudes and beliefs about others' ability and competitiveness. Women but not men are influenced by the riskiness of the tournament, and beliefs about other's ability influence the decision to enter a tournament. We measure the extent to which gender information affects behavior indirectly, through genderconditioned beliefs about others' ability and pay scheme choices, and whether there is a direct effect on behavior of knowing others' gender, possibly due to the presence of a preference for discriminating between men and women, or due to commonly held genderconditioned beliefs about others' behavior (Holm, 2000). We find that the strength of the direct effect depends on the exact way the gender information is provided. When using the Strong gender information procedure, men compete more when matched with women than with men. There is, however, no analogous result for women. The direct effect seems to be based on a preference-based taste for discrimination among men rather than the people using gender as a coordination device. When we use a weaker procedure to provide gender information, there is no direct effect. Turning to indirect effects, we find that the beliefs about other individuals' competitiveness are gender-conditioned: the more competitive a female co-participant is expected to be, the more likely both men and women are to choose the tournament. Beliefs about men's competitiveness have no impact on men's decisions and only a marginal influence on women's.

The finding that both men and women are more likely to compete against women who are expected to compete themselves may at first seem surprising. We offer two possible explanations. One possibility is that an expectation that a woman will compete triggers 
non-monetary components in both men's and women's utility functions, such as spite or envy. By this we mean an aversion to letting the woman be the only one who chooses the tournament and to letting the woman get the winner's prize 'without a fight'. Another possibility relates to social norms or expectations of conventional behavior. There can be a common social practice that holds women up to more scrutiny than men, particularly in traditionally male-dominated spheres (see Eagly, 1995). Recent evidence pointing to the importance of social learning and culture comes notably from Gneezy et al. (2009). It should be noted that most of these findings, including ours, result from one-shot games in which participants are not given a chance to learn and to to update their beliefs regarding other individuals' ability and willingness to compete. A natural extension would be to allow for repeated interactions.

We also study the optimality of the observed pay scheme choices. The predominant form of sub-optimality is that people choose the piece rate when they should have chosen the tournament, and women make this mistake much more frequently than men. It is thus not the case that 'men compete too much', but rather that 'women compete too little'. What environmental changes can lead to a reduction of the gap in competitiveness by increasing women's competitiveness? First, offering higher monetary incentives in the tournament makes women compete more, but does not reduce the gap. Second, when women can choose between interacting with men or women the gender gap in competitiveness is reduced, perhaps due to an increased feeling of confidence of women (such as when relative performance feedback is provided, see Wozniak et al., 2010), but it remains high. This suggests that more targeted policies are necessary to reduce this gap in competitiveness, such as affirmative action (Niederle et al., 2008), quotas or preferential treatment (Balafoutas and Sutter, 2010). 


\section{REFERENCES}

Altonji, Joseph G. and Blank, Rebecca, (1999). "Race and Gender in the Labor Market," O. Ashenfelter and D. Card, Handbook of Labor Economics. Amsterdam: Elsevier Science, 3144-259.

Ayres, Ian and Siegelman, Peter, (1995). "Race and Gender Discrimination in Bargaining for a New Car." American Economic Review, 85, 304-21.

Balafoutas, Loukas and Sutter, Matthias, (2010). "Gender, competition and the efficiency of policy interventions." IZA Discussion Paper 4955.

Barber, Brad M. and Odean, Terrance, (2001). "Boys Will Be Boys: Gender, Overconfidence, and Common Stock Investment." Quarterly Journal of Economics, 261-92.

Barsky, Robert B.; Juster, Thomas F.; Kimball, Miles S. and Shapiro, Matthew D., (1997). "Preference Parameters and Behavioral Heterogeneity: An Experimental Approach in the Health and Retirement Study." Quarterly Journal of Economics, 112, 537-79.

Bertrand, Marianne and Hallock, Kevin F., (2001). "The Gender Gap in Top Corporate Jobs." Industrial and Labor Relations Review, 55(1), 3-21.

Blau, Francine; Simpson, Patricia and Anderson, Deborah, (1998). "Continuing Progress? Trends in Occupational Segregation in the United States over the 1970s and 1980s." NBER Working Paper no. 6716.

Booth, Alison L., and Nolan, Patrick J., (2009). "Choosing to compete: How different are girls and boys?" CEPR Discussion Paper 7214.

Borghans, Lex; Goldsteyn, Bart H.H.; Heckman, James J. and Meijers, Huub, (2009). "Gender Differences in Risk Aversion and Ambiguity Aversion." Journal of the European Economic Association, 7(2-3), 649-58.

Boschini, Anne and Sjögren, Anna, (2007). "Is Team Formation Gender Neutral? Evidence from Coauthorship Patterns," Journal of Labor Economics, 25(2), 325-65.

Brown, Charles, (1990). "Firm's Choice of Method of Pay." Industrial and Labor Relations Review, 43, 165-82.

Cadsby, C. Bram and Maynes, Elizabeth, (1998). "Gender and Free-Riding in a Threshold Public Goods Game: Experimental Evidence." Journal of Economic Behavior and Organization, 34, 603-20.

Camerer, Colin F. and Lovallo, Dan, (1999). "Overconfidence and Excess Entry: An Experimental Approach." American Economic Review, 89(1), 306-18.

Charness, Gary and Gneezy, Uri, (2007). "Strong Evidence for Gender Differences in Financial Investment." Available at SSRN: http://ssrn.com/abstract=648735.

Croson, Rachel and Gneezy, Uri, (2009). "Gender Differences in Preferences." Journal of Economic Literature, 47(2), 448-74.

Daly, Martin and Wilson, Margo, (1983). Sex, evolution, and behavior. Boston: Willard Grant Press.

Dohmen, Thomas, and Falk, Armin, (2010). "Performance Pay and Multi-dimensional Sorting - Productivity, Preferences and Gender. "American Economic Review, forthcoming.

Dreber, Anna; von Essen, Emma and Ranehill, Eva, (2009). "Outrunning the Gender Gap Boys and Girls Compete Equally." SSE/EFI Working Paper 709. 
Eagly, Alice H., (1995). "The Science and Politics of Comparing Women and Men", American Psychologist, 50(3), 145-158.

Eckel, Catherine C., (2005). "Measuring Risk." North American meeting of the Economic Science Association, Tucson, Arizona.

Eckel, Catherine C. and Grossman, Philip J., (2001). "Chivalry and Solidarity in Ultimatum Games." Economic Inquiry, 39(2), 171-88.

, (2008). "Forecasting Risk Attitudes: An Experimental Study Using Actual and Forecast Gamble Choices.", Journal of Economic Behavior and Organization, 68 (1), $1-17$.

Gneezy, Uri; Niederle, Muriel and Rustichini, Aldo, (2003). "Performance in Competitive Environments: Gender Differences." Quarterly Journal of Economics, 1049-74.

Gneezy, Uri and Rustichini, Aldo, (2004). "Gender and Competition at a Young Age." American Economic Review (Papers and Proceedings), 94(2), 377-81.

Gneezy, Uri; Leonard, Kenneth L. and List, John A., (2009). "Gender Differences in Competition: Evidence from a Matrilineal and a Patriarchal Society." Econometrica, 77(5), 1637-1664.

Goldin, Claudia, (1986). "The Gender Gap in Historical Perspective, 1800 to 1980," P. Kilby, Quantity and Quality: Essays in American Economic History. Wesleyan: Wesleyan University Press.

Goldin, Claudia and Rouse, Cecilia, (2000). "Orchestrating Impartiality: The Impact of "Blind" Auditions on Female Musicians." American Economic Review, 90(4), 715-41.

Heywood, John S. and Jirjahn, Uwe, (2002). "Payment Schemes and Gender in Germany." Industrial and Labor Relations Review, 56(1), 44-64.

Heywood, John S.; Siebert, W.Stanley and Wei, Xiangdong, (1997). "Payment by Results Systems: British Evidence." British Journal of Industrial Relations, 35, 1-22.

Holm, Hakan, (2000). "Gender-Based Focal Points." Games and Economic Behavior, 32, 292-314.

Ingram, Barbara L. and Berger, Stephen E., (1977). "Sex-Role Orientation, Defensiveness, and Competitiveness in Women." Journal of Conflict Resolution, 21(3), 501-18.

Ivanova Stenzel, Radosteva and Kübler, Dorothea (2005). "Courtesy and Iddleness: Gender Differences in Team Work and Team Competition." SFB Discussion Paper 2005-049.

Jianokoplos, Nancy A. and Bernasek, Alexandra, (1998). "Are Women More RiskAverse?" Economic Inquiry, 36, 620-30.

Jirjahn, Uwe and Stephan, Gesine, (2004). "Gender, Piece rates and Wages: Evidence from Matched Employer-Employee Data." Cambridge Journal of Economics, 28(5), 683704.

Kahneman, Daniel and Lovallo, Dan, (1993). "Timid Choice and Bold Forecasts: A Cognitive Perspective on Risk Taking." Management Science, 39(1), 17-31.

Knight, Jonathan, (2002). "Sexual Stereotypes." Nature, 415, 254-56.

Lichtenstein, Sarah; Fischhoff, Baruch and Phillips, Lawrence, (1982). "Calibration of Probabilities: The State of the Art to 1980," D. Kahneman, P. Slovic and A. Tversky, Judgment under Uncertainty: Heuristics and Biases. Cambridge: Cambridge University Press,

Mincer, Jacob and Polachek, Solomon W., (1974). "Family Investments in Human Capital: Earnings of Women." Journal of Political Economy, 82(2), S76-S108. 
Neumark, David; Blank, Roy J. and Van Nort, Kyle D., (1996). "Sex Discrimination in Restaurant Hiring: An Audit Study." Quarterly Journal of Economics, 111(3), 915-41.

Niederle, Muriel and Vesterlund, Lise, (2007). "Do Women Shy Away from Competition? Do Men Compete Too Much?" Quarterly Journal of Economics, 122(3), 1067-1101.

Niederle, Muriel; Segal, Carmit and Vesterlund, Lise, (2008). "How costly is diversity? Affirmative action in the light of gender differences in competitiveness", NBER Working Paper no. 13923.

Polachek, Solomon W., (1981). "Occupational Self-Selection: A Human Capital Approach to Sex Differences in Occupational Structure." Review of Economics and Statistics, 63(1), 60-69.

Powell, Melanie and Ansic, David, (1997). "Gender Differences in Risk Behavior in Financial Decision-Making: An Experimental Analysis." Journal of Economic Psychology, 18, 605-28.

Rapoport, Anatol and Chammah, Albert M., (1965). "Sex Differences in Factors Contributing to the Level of Cooperation in the Prisoner's Dilemma Game." Journal of Personality and Social Psychology, 2(6), 831-38.

Slonim, Robert, (2006). "Gender Selection Discrimination: Evidence from a Trust Game." Case Western Reserve University, Mimeo.

Slonim, Robert and Garbarino, Ellen, (2007). "Increases in trust and altruism from partner selection: experimental evidence." Experimental Economics, 11 (2), 134-153.

Sutter, Matthias; Bosman, Ronald; Kocher, Martin and van Winden, Franz, (2009). "Gender pairing and bargaining - Beware the same sex!" Experimental Economics, 12(3), 318-331.

Sutter, Matthias and Rützler, Daniela, (2010). "Gender differences in competition emerge early in life: Three-year old girls compete as much as boys, but older girls don't." University of Innsbruck, mimeo.

Taylor, Shelley E. and Brown, Jonathan D., (1988). "Illusion and Well-Being: A Social Psychological Perspective on Mental Health." Psychological Bulletin, 103(2), 193210.

Vandegrift, Donald and Brown, Paul M., (2005). "Gender differences in the use of highvariance strategies in tournament competition." Journal of Socio-Economics, 34 (6), 834-849.

Vandegrift, Donald and Yavas, Abdullah, (2009). "Men, Women, and Competition: An Experimental Test of Labor Market Behavior." Journal of Economic Behavior and Organization, 72(1), 554-570.

Weber, Elke U.; Blais, Ann-Renée and Betz, Nancy E., (2002). "A Domain-Specific RiskAttitude Scale: Measuring Risk Perceptions and Risk Behaviors." Journal of Behavioral Decision Making, 15, 263-90.

Wozniak, Daniel; Harbaugh, William T. and Mayr, Ulrich, (2010). "Choices About Competition: Differences by gender and hormonal fluctuations and the role of relative performance feedback." University of Oregon, mimeo.

Zeiliger, Romain, (2000). A Presentation of Regate, Internet Based Software for Experimental Economics. http://www.gate.cnrs.fr/ zeiliger/regate/RegateIntro.ppt., GATE. 
Table 1. Descriptive statistics on payment scheme choices and maze solving performance a) Weak gender information procedure

\begin{tabular}{|c|c|c|c|}
\hline \multirow[t]{2}{*}{ Participant's gender } & \multicolumn{2}{|c|}{ Co-participant's gender } & \multirow[t]{2}{*}{ All } \\
\hline & Female & Male & \\
\hline \multicolumn{4}{|c|}{ Distribution of payment schemes in absolute numbers by gender (\% in parentheses) } \\
\hline Females & $32(100.00)$ & $18(100.00)$ & $50(100.00)$ \\
\hline Piece rate & $21(65.62)$ & $12(66.67)$ & $33(66.00)$ \\
\hline Tournament & $11(34.38)$ & $6(33.33)$ & $17(34.00)$ \\
\hline - without competition & $7(21.88)$ & $3(16.67)$ & $10(20.00)$ \\
\hline - with competition & $4(12.50)$ & $3(16.67)$ & $7(14.00)$ \\
\hline Males & $18(100.00)$ & $32(100.00)$ & $50(100.00)$ \\
\hline Piece rate & $8(44.44)$ & $12(37.50)$ & $20(40.00)$ \\
\hline Tournament & $10(55.56)$ & $20(62.50)$ & $30(60.00)$ \\
\hline - without competition & $7(38.89)$ & $8(25.00)$ & $15(30.00)$ \\
\hline - with competition & $3(16.67)$ & $12(37.50)$ & $15(30.00)$ \\
\hline \multicolumn{4}{|c|}{$\begin{array}{l}\text { Average number of mazes solved by gender and payment scheme (standard deviations in } \\
\text { parentheses) }\end{array}$} \\
\hline Females & $10.72(3.20)$ & $9.83(3.07)$ & $10.40(3.15)$ \\
\hline Piece rate & $11.00(3.32)$ & $9.67(3.20)$ & $10.52(3.29)$ \\
\hline Tournament & $10.18(3.03)$ & $10.17(3.06)$ & $10.18(2.94)$ \\
\hline - without competition & $10.14(3.76)$ & $8.33(2.08)$ & $9.60(3.34)$ \\
\hline - with competition & $10.25(1.50)$ & $12.00(3.00)$ & $11.00(2.24)$ \\
\hline Males & $11.61(3.16)$ & $13.41(3.59)$ & $12.76(3.52)$ \\
\hline Piece rate & $11.50(3.42)$ & $11.67(3.87)$ & $11.60(3.60)$ \\
\hline Tournament & $11.70(3.13)$ & $14.45(3.05)$ & $13.53(3.30)$ \\
\hline - without competition & $12.86(2.34)$ & $16.00(2.20)$ & $14.53(2.72)$ \\
\hline - with competition & $9.00(3.46)$ & $13.42(3.18)$ & $12.53(3.60)$ \\
\hline
\end{tabular}


b) Strong gender information procedure

\begin{tabular}{|c|c|c|c|}
\hline \multirow[t]{2}{*}{ Participant's gender } & \multicolumn{2}{|c|}{ Co-participant's gender } & \multirow[t]{2}{*}{ All } \\
\hline & Female & Male & \\
\hline \multicolumn{4}{|c|}{ Distribution of payment schemes in absolute numbers by gender (\% in parentheses) } \\
\hline Females & $12(100.00)$ & $8(100.00)$ & $20(100.00)$ \\
\hline Piece rate & $9(75.00)$ & $6(75.00)$ & $15(75.00)$ \\
\hline Tournament & $3(25.00)$ & $2(25.00)$ & $5(25.00)$ \\
\hline - without competition & $3(25.00)$ & $0(0.00)$ & $3(15.00)$ \\
\hline - with competition & $0 \quad(0.00)$ & $2(25.00)$ & $2(10.00)$ \\
\hline Males & $8(100.00)$ & $12(100.00)$ & $20(100.00)$ \\
\hline Piece rate & $3(37.50)$ & $8(66.67)$ & $11(55.00)$ \\
\hline Tournament & $5(62.50)$ & $4(33.33)$ & $9(45.00)$ \\
\hline - without competition & $2(25.00)$ & $4(33.33)$ & $6(30.00)$ \\
\hline - with competition & $3(37.50)$ & $0(0.00)$ & $3(15.00)$ \\
\hline \multicolumn{4}{|c|}{$\begin{array}{l}\text { Average number of mazes solved by gender and payment scheme (standard deviations in } \\
\text { parentheses) }\end{array}$} \\
\hline Females & $12.17(2.69)$ & $13.25(3.77)$ & $12.06(3.12)$ \\
\hline Piece rate & $11.78(3.03)$ & $13.33(4.27)$ & $12.40(3.52)$ \\
\hline Tournament & $13.33(0.58)$ & $13.00(2.83)$ & $13.20(1.48)$ \\
\hline - without competition & $13.33(0.58)$ & $-(-)$ & $13.33(0.58)$ \\
\hline - with competition & $-(-)$ & $13.00(2.83)$ & $13.00(2.83)$ \\
\hline Males & $12.50(2.62)$ & $13.58(3.40)$ & $13.15(3.08)$ \\
\hline Piece rate & $12.67(4.04)$ & 13.25 (3.99) & $13.09(3.81)$ \\
\hline Tournament & $12.40(1.95)$ & $14.25(2.06)$ & $13.22(2.11)$ \\
\hline - without competition & $12.50(2.12)$ & $14.25(2.06)$ & $13.67(2.07)$ \\
\hline - with competition & $12.33(2.31)$ & $-(-)$ & $12.33(2.31)$ \\
\hline
\end{tabular}


Table 2. Determinants of the tournament payment scheme choice (probit models)

\begin{tabular}{|c|c|c|c|c|}
\hline $\begin{array}{l}\text { Dependent variable: Tournament } \\
\text { entry }\end{array}$ & $\begin{array}{r}\text { All } \\
(1) \\
\end{array}$ & $\begin{array}{l}\text { All } \\
(2)\end{array}$ & $\begin{array}{c}\text { Women } \\
\text { (3) }\end{array}$ & $\begin{array}{c}\text { Men } \\
(4)\end{array}$ \\
\hline Male participant & $\begin{array}{c}0.974 * * * \\
(0.067)\end{array}$ & - & - & - \\
\hline $\begin{array}{l}\text { Male participant }- \text { Strong } \\
\text { information procedure }\end{array}$ & $\begin{array}{c}0.235 \\
(0.220)\end{array}$ & - & - & - \\
\hline Male co-participant & $\begin{array}{r}-0.020 \\
(0.526)\end{array}$ & - & $\begin{array}{c}0.384 \\
(0.838)\end{array}$ & $\begin{array}{c}0.029 \\
(0.851)\end{array}$ \\
\hline $\begin{array}{l}\text { Male co-participant } \\
\text { - Strong information procedure }\end{array}$ & $\begin{array}{l}-0.371^{* * *} \\
(0.135)\end{array}$ & - & $\begin{array}{l}-0.213 \\
(0.188)\end{array}$ & $\begin{array}{c}-0.639 * * * \\
(0.141)\end{array}$ \\
\hline Man matched with a man & - & $\begin{array}{c}0.965 * * * \\
(0.058)\end{array}$ & - & - \\
\hline $\begin{array}{l}\text { Man matched with a man - } \\
\text { Strong information procedure }\end{array}$ & - & $\begin{array}{c}0.002 \\
(0.312)\end{array}$ & - & - \\
\hline Man matched with a woman & - & $\begin{array}{c}0.880 * * * \\
(0.095)\end{array}$ & - & - \\
\hline $\begin{array}{l}\text { Man matched with a woman- } \\
\text { Strong information procedure }\end{array}$ & - & $\begin{array}{c}0.559 * * * \\
(0.157)\end{array}$ & - & - \\
\hline Woman matched with a woman & - & $\begin{array}{c}0.006 \\
(0.544)\end{array}$ & - & - \\
\hline $\begin{array}{l}\text { Woman matched with a woman- } \\
\text { Strong information procedure }\end{array}$ & - & $\begin{array}{c}0.201 \\
(0.344)\end{array}$ & - & - \\
\hline $\begin{array}{l}\text { Strong gender information } \\
\text { procedure }\end{array}$ & $\begin{array}{c}0.060 \\
(0.191)\end{array}$ & $\begin{array}{l}-0.256 \\
(0.220)\end{array}$ & $\begin{array}{c}0.097 \\
(0.238)\end{array}$ & $\begin{array}{l}0.426^{*} \\
(0.220)\end{array}$ \\
\hline Risk score & $\begin{array}{c}0.026^{* *} \\
(0.012)\end{array}$ & $\begin{array}{c}0.029 * * \\
(0.012)\end{array}$ & $\begin{array}{c}0.034 * * * \\
(0.013)\end{array}$ & $\begin{array}{l}-0.015 \\
(0.015)\end{array}$ \\
\hline Risk score $*$ man & $\begin{array}{r}-0.038^{* *} \\
(0.016)\end{array}$ & $\begin{array}{c}-0.042 * * \\
(0.017)\end{array}$ & - & - \\
\hline $\begin{array}{l}\text { Predicted entry rate of men if } \\
\text { male co-participant }\end{array}$ & $\begin{array}{c}0.004 \\
(0.004)\end{array}$ & $\begin{array}{l}0.004 \\
(0.004)\end{array}$ & $\begin{array}{l}0.013^{*} \\
(0.007)\end{array}$ & $\begin{array}{l}<0.001 \\
(0.005)\end{array}$ \\
\hline $\begin{array}{l}\text { Predicted entry rate of women if } \\
\text { female co-participant }\end{array}$ & $\begin{array}{r}0.014 * * * \\
(0.005)\end{array}$ & $\begin{array}{l}0.014 * * * \\
(0.005)\end{array}$ & $\begin{array}{l}0.011 * \\
(0.006)\end{array}$ & $\begin{array}{c}0.016^{* *} \\
(0.007)\end{array}$ \\
\hline $\begin{array}{l}\text { Predicted ability of men if male } \\
\text { co-participant }\end{array}$ & $\begin{array}{r}-0.075 * * \\
(0.039)\end{array}$ & $\begin{array}{c}-0.083 * * \\
(0.039)\end{array}$ & $\begin{array}{r}-0.182 * * * \\
(0.069)\end{array}$ & $\begin{array}{l}-0.044 \\
(0.055)\end{array}$ \\
\hline $\begin{array}{l}\text { Predicted ability of women if } \\
\text { female co-participant }\end{array}$ & $\begin{array}{c}-0.132 * * * \\
(0.040)\end{array}$ & $\begin{array}{c}-0.144 * * * \\
(0.042)\end{array}$ & $\begin{array}{c}-0.144 * * * \\
(0.051)\end{array}$ & $\begin{array}{c}-0.125^{*} \\
(0.070)\end{array}$ \\
\hline Own ability & $\begin{array}{c}0.094 * * * \\
(0.028)\end{array}$ & $\begin{array}{c}0.103 * * * \\
(0.030)\end{array}$ & $\begin{array}{c}0.098 * * \\
(0.039)\end{array}$ & $\begin{array}{c}0.120 * * * \\
(0.045)\end{array}$ \\
\hline $\begin{array}{l}\text { Other demographics (age and } \\
\text { experience) }\end{array}$ & Yes & Yes & Yes & Yes \\
\hline $\operatorname{LR} \chi^{2}$ & 33.38 & 35.25 & 26.39 & 20.16 \\
\hline $\operatorname{Prob}>\chi^{2}$ & 0.002 & 0.004 & 0.006 & 0.043 \\
\hline Log Likelihood & -65.132 & -64.197 & -25.653 & -31.507 \\
\hline Pseudo $\mathrm{R}^{2}$ & 0.204 & 0.215 & 0.340 & 0.242 \\
\hline $\mathrm{N}$ & 120 & 120 & 60 & 60 \\
\hline
\end{tabular}

Note: Marginal effects are indicated with their level of significance. Standard errors are in parentheses. $*, * *$, and $* * *$ indicate statistical significance at the $0.10,0.05$, and 0.01 level, respectively. The mean values of the independent variables are displayed in Appendix 3. 
Table 3. Percentage of observed pay scheme choices that were optimal, conditional on own and co-participant's gender.

\begin{tabular}{lcccc}
\hline Actual choice & \multicolumn{2}{c}{ Piece rate } & \multicolumn{2}{c}{ Tournament } \\
\cline { 2 - 5 } & $\begin{array}{c}\text { Female } \\
\text { co-participant }\end{array}$ & $\begin{array}{c}\text { Male } \\
\text { co-participant }\end{array}$ & $\begin{array}{c}\text { Female } \\
\text { co-participant }\end{array}$ & $\begin{array}{c}\text { Male } \\
\text { co-participant }\end{array}$ \\
\hline Weak gender information procedure & & & 83.33 \\
\hline Women & 0.00 & 16.66 & 100.00 & 90.00 \\
Men & 0.00 & 58.33 & 100.00 & \\
\hline Strong gender information procedure & & & 50.00 \\
& & & & 100.00 \\
\hline Women & 0.00 & 50.00 & 100.00 & 100.00 \\
Men & 0.00 & 0.00 & & \\
\hline
\end{tabular}


Table 4. Average expected earnings gain from switching from observed sub-optimal payment scheme to other payment scheme.

\begin{tabular}{lcccc}
\hline \multirow{2}{*}{ Gender } & \multicolumn{2}{c}{$\begin{array}{c}\text { Gain from switching from piece } \\
\text { rate to tournament }\end{array}$} & $\begin{array}{c}\text { Gain from switching from tournament } \\
\text { to piece rate }\end{array}$ \\
\cline { 2 - 5 } & $\begin{array}{c}\text { Female } \\
\text { co-participant }\end{array}$ & $\begin{array}{c}\text { Male } \\
\text { co-participant }\end{array}$ & $\begin{array}{c}\text { Female } \\
\text { co-participant }\end{array}$ & $\begin{array}{c}\text { Male } \\
\text { co-participant }\end{array}$ \\
\hline Weak gender information procedure & & & $4.68(24.22 \%)$ \\
\hline Woman & $15.75(35.79 \%)$ & $12.72(18.00 \%)$ & - & $6.6(19.85 \%)$ \\
Man & $14.15(30.77 \%)$ & $15.07(24.79 \%)$ & - & $3.78(9.39 \%)$ \\
\hline Strong gender information procedure & & - & - \\
\hline Woman & $13.67(28.22 \%)$ & $34.00(50.00 \%)$ & - & \\
Man & $19.08(38.00 \%)$ & $15.95(30.09 \%)$ & - & \\
\hline
\end{tabular}

Note: Numbers are the absolute gain in points $(1$ point $=0.25$ Euro). Numbers in parentheses are the percentage gain. A "-“ indicates that there are no observations (i.e., all subjects made optimal pay scheme choices). 


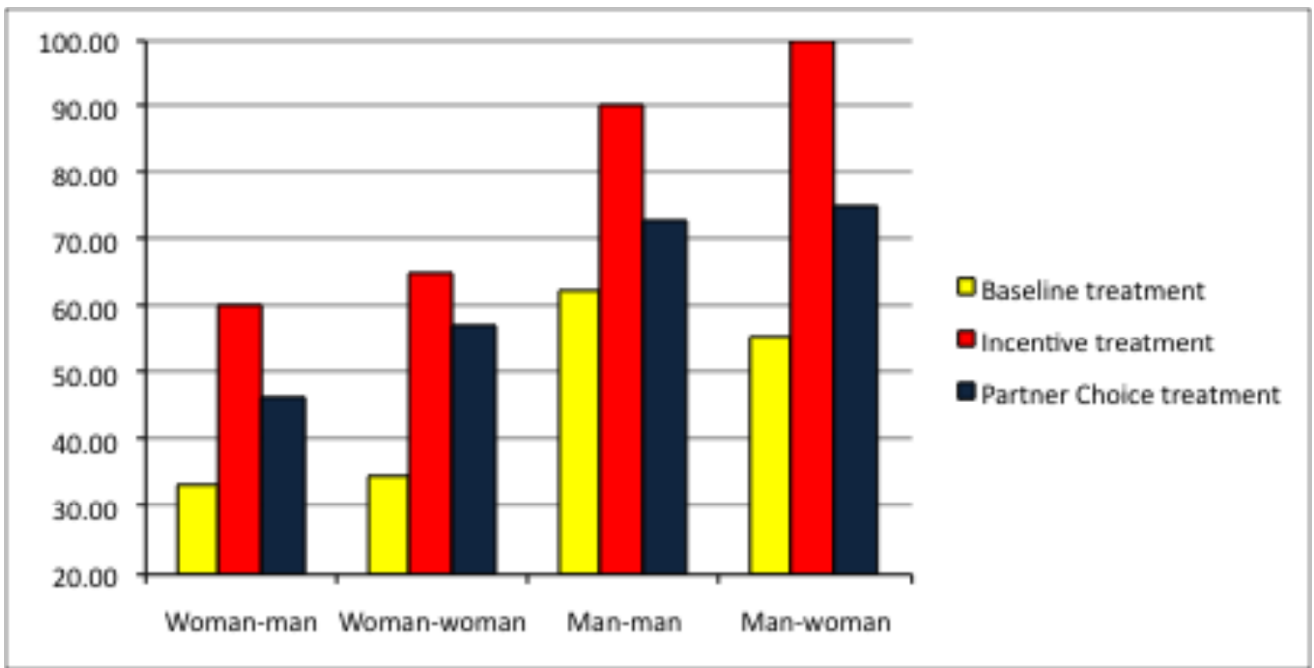

Figure 1. Percentages of individuals choosing the tournament in the Baseline, the Incentive and the Partner Choice treatments in each gender configuration 
Appendix 1. Overview of experimental sessions

\begin{tabular}{|c|c|c|c|c|}
\hline \# session & Treatment & $\begin{array}{l}\text { Information on } \\
\text { correspondence } \\
\text { of pseudonym } \\
\text { and gender }\end{array}$ & $\begin{array}{l}\text { Question on the } \\
\text { expected co- } \\
\text { participant's } \\
\text { choice }\end{array}$ & $\begin{array}{l}\text { \# participants } \\
\text { (women/men) }\end{array}$ \\
\hline 1 & Incentives & & & $20(9 / 11)$ \\
\hline 2 & Incentives & & & $20(10 / 10)$ \\
\hline 3 & Incentives & & & $20(11 / 9)$ \\
\hline 4 & Baseline & & & $20(10 / 10)$ \\
\hline 5 & Baseline & & & $20(10 / 10)$ \\
\hline 6 & Baseline & & & $20(10 / 10)$ \\
\hline 7 & Choice Partner & & & $20(10 / 10)$ \\
\hline 8 & Choice Partner & & & $20(10 / 10)$ \\
\hline 9 & Choice Partner & & & $20(10 / 10)$ \\
\hline 10 & Choice Partner & & & $20(11 / 9)$ \\
\hline 11 & Baseline & & $X$ & $20(11 / 9)$ \\
\hline 12 & Baseline & & $X$ & $20(9 / 11)$ \\
\hline 13 & Baseline & $\mathrm{X}$ & $\mathrm{X}$ & $20(10 / 10)$ \\
\hline 14 & Baseline & $X$ & $\mathrm{X}$ & $20(10 / 10)$ \\
\hline
\end{tabular}




\section{Appendix 2. Risk Distributions}
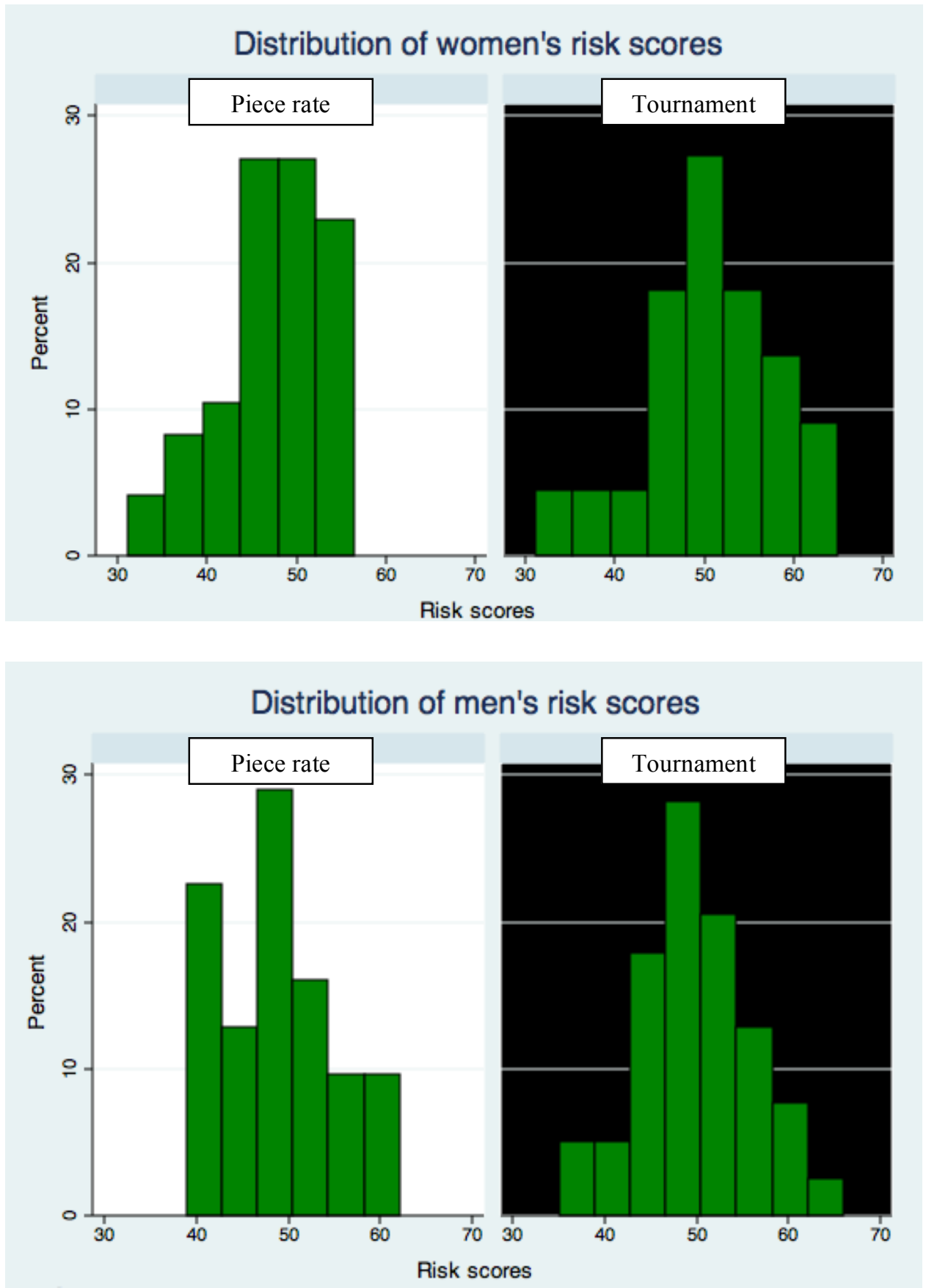

Figure 2. Distribution of risk scores by payment scheme 
Appendix 3. Mean values of the variables in the regressions reported in Table 2

\begin{tabular}{|c|c|c|c|c|}
\hline $\begin{array}{l}\text { Dependent variable: Tournament } \\
\text { entry }\end{array}$ & $\begin{array}{r}\text { All } \\
(1)\end{array}$ & $\begin{array}{l}\text { All } \\
\text { (2) }\end{array}$ & Females & Males \\
\hline Male participant & $\begin{array}{l}0.500 \\
(0.502)\end{array}$ & - & - & - \\
\hline Male participant*Strong information & $\begin{array}{c}0.167 \\
(0.374)\end{array}$ & - & - & - \\
\hline Male co-participant & $\begin{array}{c}0.500 \\
(0.502)\end{array}$ & - & $\begin{array}{c}0.367 \\
(0.486)\end{array}$ & $\begin{array}{c}0.633 \\
(0.486)\end{array}$ \\
\hline $\begin{array}{l}\text { Male co-participant* Strong } \\
\text { information }\end{array}$ & $\begin{array}{c}0.167 \\
(0.374)\end{array}$ & - & $\begin{array}{c}0.133 \\
(0.343)\end{array}$ & $\begin{array}{c}0.200 \\
(0.403)\end{array}$ \\
\hline Man matched with a man & - & $\begin{array}{c}0.317 \\
(0.467)\end{array}$ & - & - \\
\hline $\begin{array}{l}\text { Man matched with a man* Strong } \\
\text { information }\end{array}$ & - & $\begin{array}{c}0.100 \\
(0.301)\end{array}$ & - & - \\
\hline Man matched with a woman & - & $\begin{array}{c}0.183 \\
(0.389)\end{array}$ & - & - \\
\hline $\begin{array}{l}\text { Man matched with a woman* Strong } \\
\text { information }\end{array}$ & - & $\begin{array}{c}0.067 \\
(0.250)\end{array}$ & - & - \\
\hline Woman matched with a woman & - & $\begin{array}{c}0.317 \\
(0.467)\end{array}$ & - & - \\
\hline $\begin{array}{l}\text { Woman matched with a woman* } \\
\text { Strong information }\end{array}$ & - & $\begin{array}{c}0.100 \\
(0.301)\end{array}$ & - & - \\
\hline Strong information sessions & $\begin{array}{c}0.333 \\
(0.473)\end{array}$ & $\begin{array}{c}0.333 \\
(0.473)\end{array}$ & $\begin{array}{l}0.333 \\
(0.475)\end{array}$ & $\begin{array}{l}0.333 \\
(0.475)\end{array}$ \\
\hline Risk score & $\begin{array}{l}48.608 \\
(6.735)\end{array}$ & $\begin{array}{l}48.608 \\
(6.735)\end{array}$ & $\begin{array}{l}47.983 \\
(6.866)\end{array}$ & $\begin{array}{l}49.233 \\
(6.601)\end{array}$ \\
\hline Risk score * man & $\begin{array}{c}24.617 \\
(25.153)\end{array}$ & $\begin{array}{c}24.617 \\
(25.153)\end{array}$ & - & - \\
\hline $\begin{array}{l}\text { Predicted entry rate of men if male } \\
\text { co-participant }\end{array}$ & $\begin{array}{l}31.326 \\
(34.602)\end{array}$ & $\begin{array}{c}31.326 \\
(34.602)\end{array}$ & $\begin{array}{l}24.500 \\
(34.915)\end{array}$ & $\begin{array}{c}38.153 \\
(33.181)\end{array}$ \\
\hline $\begin{array}{l}\text { Predicted entry rate of women if } \\
\text { female co-participant }\end{array}$ & $\begin{array}{c}20.744 \\
(24.276)\end{array}$ & $\begin{array}{c}20.744 \\
(24.276)\end{array}$ & $\begin{array}{c}25.991 \\
(23.417)\end{array}$ & $\begin{array}{c}15.497 \\
(24.173)\end{array}$ \\
\hline $\begin{array}{l}\text { Predicted ability of men if male co- } \\
\text { participant }\end{array}$ & $\begin{array}{c}5.958 \\
(6.274)\end{array}$ & $\begin{array}{c}5.958 \\
(6.274)\end{array}$ & $\begin{array}{c}4.283 \\
(5.926)\end{array}$ & $\begin{array}{l}7.633 \\
(6.211)\end{array}$ \\
\hline $\begin{array}{l}\text { Predicted ability of women if female } \\
\text { co-participant }\end{array}$ & $\begin{array}{c}5.017 \\
(5.394)\end{array}$ & $\begin{array}{c}5.017 \\
(5.394)\end{array}$ & $\begin{array}{c}6.350 \\
(5.355)\end{array}$ & $\begin{array}{l}3.683 \\
(5.137)\end{array}$ \\
\hline Own ability & $\begin{array}{r}11.992 \\
(3.501)\end{array}$ & $\begin{array}{l}11.992 \\
(3.501)\end{array}$ & $\begin{array}{l}11.100 \\
(3.338)\end{array}$ & $\begin{array}{l}12.883 \\
(3.460)\end{array}$ \\
\hline Age & $\begin{array}{l}21.733 \\
(2.393)\end{array}$ & $\begin{array}{l}21.733 \\
(2.393)\end{array}$ & $\begin{array}{l}21.200 \\
(1.735)\end{array}$ & $\begin{array}{l}22.267 \\
(2.822)\end{array}$ \\
\hline Experience & $\begin{array}{c}0.575 \\
(0.496)\end{array}$ & $\begin{array}{c}0.575 \\
(0.496)\end{array}$ & $\begin{array}{c}0.533 \\
(0.503)\end{array}$ & $\begin{array}{c}0.617 \\
(0.490)\end{array}$ \\
\hline $\mathrm{N}$ & 120 & 120 & 60 & 60 \\
\hline
\end{tabular}

Note that the mean values of the variables interacted with a dummy variable are relatively low since the interacted dummy variable is either equal to 1 or to 0 . Standard errors are in parentheses. 


\title{
Gender matching and competitiveness: Experimental evidence
}

\author{
Data Gupta, N., Poulsen, A., Villeval, M.C.
}

Economic Inquiry, 2011

Supplementary material (SM)

\section{SM1. Instructions}

\section{(These instructions are for the Baseline treatment - the instructions for the other treatments are available upon request)}

You are participating in an experiment on decision-making. During this session, you can earn money. The amount of your earnings depends on your decisions and the decisions of another participant you will interact with. During the session, your earnings are expressed in points with the following conversion rule:

$$
1 \text { point }=0.25 €
$$

At the end of the session, you will be paid in cash your earnings obtained during this session after they have been converted into Euros. We will add up to these earnings an additional amount of money (a show-up fee of $2 €+$ a minimum amount of $2 €$ for your participation to a post-experimental questionnaire). You will get paid in a separate room in order to preserve confidentiality, on presentation of the ticket that you have randomly drawn from the envelope upon entering the laboratory. The whole session lasts about one hour long.

Before starting the session, you are kindly requested to supply some personal information about your gender, your age, your school, your level and field of studies and whether you have already participated in an experiment in economics. These anonymous pieces of information will remain confidential.

During this session, you will perform a task on your computer. This task consists of solving mazes. You are going to practice now by solving three mazes in order to get familiar with the task at hand.

As soon as you click the button "start", a maze appears on your screen. Starting from the green point located at the left of your screen, you can move around in this maze by using the mouse of your computer. The path you follow appears in green and a marker always indicates your current position in the maze. You can move forward, stop or restart from any point already reached whenever you want. You can also give up a maze before solving it and make another one appear by clicking the button "next". The maze is solved as soon as you reach the red point located at the right of the screen. You are always shown the time you have spent since you clicked the "start" button. All the participants can see the same three mazes.

When you have completed these three practice periods, you will be requested to answer the following question: "In your opinion, how many mazes do you think you could solve in 15 minutes?". The results of these practice periods and the answer to this question have definitely no consequences for the rest of the session, either for the person you will interact with, or for your earnings. After a moment, you will receive the instructions for the rest of the session.

If you have any questions, please raise your hand. Someone will answer your questions privately. Throughout the entire session, talking is not allowed.

\section{Instructions (continued)}


[The instructions below were distributed to the participants when all of them had completed the practice periods and answered the question]

During this session, you are paired with another participant.

Both you and the participant you are paired with have to perform a task. The task consists of solving mazes during a limited period of time of 15 minutes. The number of mazes you solve contributes to determine your earnings. The session consists of two stages.

In the first stage, you are allocated a pseudonym(a fake first name) and we inform you on the pseudonym given to your co-participant. Your co-participant is simultaneously informed on your pseudonym. If you are a woman, your pseudonym is a female name, and if you are a man your pseudonym is a male name. Similarly, if your coparticipant is a man, his pseudonym will be a male name, and if your co-participant is a woman, her pseudonym will be a female name. [The last two sentences were only mentioned in the two sessions of the Baseline treatment with more salient information on gender]

Next, you choose simultaneously between two possible modes of payment, Mode A and Mode B. Your choice of the mode of payment and the choice of your co-participant determine the number of points you receive for each maze you solve personally.

\begin{tabular}{|c|c|c|c|c|}
\hline You choose & $\begin{array}{c}\text { And your co- } \\
\text { participant } \\
\text { chooses }\end{array}$ & \multicolumn{3}{|c|}{ You receive personally } \\
\hline Mode A & $\begin{array}{l}\text { Mode A } \\
\text { or mode B }\end{array}$ & \multicolumn{3}{|c|}{$\begin{array}{l}4 \text { points for each maze you solve, no matter the number of } \\
\text { mazes solved by the participant you are paired with }\end{array}$} \\
\hline Mode B & Mode A & \multicolumn{3}{|c|}{$\begin{array}{l}6 \text { points for each maze you solve, no matter the number of } \\
\text { mazes solved by the participant you are paired with }\end{array}$} \\
\hline Mode B & Mode B & $\begin{array}{l}6 \text { points for each } \\
\text { maze you solve if } \\
\text { you solve more } \\
\text { mazes than your } \\
\text { co-participant }\end{array}$ & $\begin{array}{l}1 \text { point for each } \\
\text { maze you solve if } \\
\text { you solve fewer } \\
\text { mazes than your } \\
\text { co-participant. }\end{array}$ & $\begin{array}{l}\text { If you solve the } \\
\text { same number of } \\
\text { mazes as your co- } \\
\text { participant, a } \\
\text { random draw } \\
\text { determines which } \\
\text { of you two receives } \\
6 \text { points for each } \\
\text { maze solved and } \\
\text { which of you two } \\
\text { receives } 1 \text { point for } \\
\text { each maze solved. }\end{array}$ \\
\hline
\end{tabular}

You choose between Mode A and Mode B by clicking one of the two buttons available on your computer screen. Your choice is registered once you click "OK".

You are informed of the choice of your co-participant before moving to the second stage and your co-participant is informed on your choice.

In the second stage, you perform the task of solving mazes during 15 minutes. Time is deducted as soon as you click the "start" button. To make a new maze appear on your screen, you can click the "next" button. The number of mazes you have currently solved is always visible on your screen, as the time already spent since the beginning of the task solving. All the mazes have a solution. All the participants receive the same mazes in the same order.

At the end of the 15-minute period, you are informed about your payoff and the session is over. Then you are asked to fill out a post-experimental questionnaire, the details of which will be shown on your screen.

If you have any questions, please raise your hand. Someone will answer your questions privately. 


\section{SM2. Post-experimental questionnaire}

You are kindly requested to answer the following questionnaire that consists of two parts. By answering these questions, you can earn between 2 and 6 Euros more. The answers to these questions are anonymous and confidential. Communication is not allowed.

\section{$1^{\text {st }}$ part. You will receive 1 Euro for each correct answer to the following questions.}

For your information, in this session, there were women and men.

Question 1. In your opinion, what is the average number of mazes solved by the women in this session (including yourself if you are a woman)?

Question 2. In your opinion, what is the average number of mazes solved by the men in this session (including yourself if you are a man)?

Question 3. In your opinion, how many women in this session have chosen mode B (including yourself if you are a woman)?

Question 4. In your opinion, how many men in this session have chosen mode B (including yourself if you are a man)?

\section{$2^{\text {nd }}$ part. You earn $2 €$ for sure by answering the following 16 questions.}

For each of the following statements, please indicate the likelihood that you engage in each activity or behavior, by using the following scale, and by entering a number between 1 (very unlikely) and 5 (very likely):

\begin{tabular}{c|c|c|c|c}
\hline 1 & 2 & 3 & 4 & 5 \\
Very unlikely & Unlikely & Not sure & Likely & Very likely
\end{tabular}

Betting a day's income at a high stake playing cards game :

Getting close to a river in flood to take pictures that you can sell to the press:

Investing $10 \%$ of your annual income in a moderate growth mutual fund:

Defending an unpopular issue that you believe in at a social occasion:

Co-signing a new car loan for a friend:

Deciding to share an apartment with somebody you don't know well:

Investing $5 \%$ of your annual income in a very speculative stock:

Going camping in the wild:

Taking a week's income to play at the casino:

Going on a two-week vacation in a third-world country without

prearranged hotel accommodation:

Spending money impulsively without thinking about the consequences:

Trying bungee jumping:

Lending a friend an amount of money equivalent to one month 's income:

Investing in a business that has a good chance of failing: 
Approaching your boss to ask for a raise:

Dating someone you are working with:

\section{SM3. Tests of robustness of our procedures}

The beliefs about payment scheme choices are measured after the participant received feedback about the co-participant's choice. A participant thus knew the choice of one participant out of 19 other participants in the session, and this could have influenced his reported beliefs. Therefore, we compare the beliefs of women when their co-participant of a specific gender has chosen the piece rate with their beliefs when the co-participant of the same gender has chosen the tournament. The same comparisons are made for men. MannWhitney tests indicate that neither women nor men's beliefs are influenced by their coparticipant's decision. Women report similar beliefs on entry rates when their co-participant has chosen the piece rate and when he has chosen the tournament $(p=0.302$ when matched with a woman and $p=0.945$ when matched with a man), and similarly for men $(p=0.409$ when matched with a woman and $p=0.794$ when matched with a man).

Furthermore, in four sessions participants stated their beliefs about their co-participant's choice after they had made their own payment scheme choice, but before they learned the coparticipant's choice. An accurate answer was paid $€ 1$. We find that among those participants who were matched with a woman and who believed this woman entered the tournament (did not enter), $66.67 \%$ (29.03\%, respectively) chose the tournament. Among those participants who were matched with a man and who believed this man entered the tournament (did not enter), $47.62 \%$ ( $21.05 \%$, respectively) chose the tournament. This suggests that expecting the co-participant to enter the competition increases the individual's likelihood of competing, especially if the co-participant is a woman. This is consistent with the findings reported in Table 2. Eliciting beliefs about their co-participant's payment scheme choice before or after they learned the co-participant's choice leads to the same qualitative analysis.

Consider next the measurement of beliefs about ability. Here a potential bias could arise due to the fact that a participant states his belief after he has been informed on whether he won or lost the tournament in case both players competed. A participant never received any feedback on the performance of his co-participant, but in a two-person tournament he knew whether he performed better or not. This information might have influenced the beliefs about performance levels. Whereas eliciting beliefs before decision-making could have focused participants' attention on the co-participant's gender and hence affected their decisions artificially, eliciting them before informing the participants about the competition outcome could have been preferable. In fact, the data shows that being informed about one's success or failure does not impact the predictions. Mann-Whitney tests indicate that among those participants matched with women, there is no significant difference in beliefs about female performance between those who were involved in a two-person tournament and those who chose the tournament but did not compete $(p=0.736)$. Also, there is no significant difference in beliefs between the winners and the losers of these two-person tournaments $(p=0.245)$. The conclusions are similar when one considers participants who were matched with a man and chose the tournament ( $p=0.979$ and $p=0.124$, respectively). We thus believe that there is no noticeable bias in the way we elicited beliefs about other participants' payment scheme choices and abilities. 